\title{
AKTIVITAS ANTIBAKTERI DAN ANTIOKSIDAN ISOLAT FRAKSI ETIL ASETAT BUAH LIBO (Ficus variegata Blume.)
}

\author{
Bela Apriliana Ningsih*, Agung Rahmadani, Jaka Fadraersada, Rolan Rusli \\ Laboratorium Penelitian dan Pengembangan FARMAKA TROPIS Fakultas Farmasi \\ Universitas Mulawarman, Samarinda, Kalimantan Timur \\ *email: bela.apriliana25@gmail.com
}

\begin{abstract}
This research has been done in order to know antibacterial and antioxidant activity in ethyl acetate subfraction of Libo fruits (Ficus variegata Blume.). Extraction was done by maceration method using methanol and n-hexane. Isolation was done by 2 methods were vacuum liquid chromatography (VLC) and followed by conventional column chromatography. Eluent were used n-hexane-ethyl acetate. 4 subfractions were obtained by conventional column chromatography. Subfractions were conducted qualitative antibacterial activity testing using bioautography thin layer chromatography (TLC) method and antioxidant activity testing using DPPH method. The results were chromatographic profile of subfraction F1 and F4 has one spot while subfraction of F2 and F3 have two spots. All of subfractions have an antibacterial and antioxidan activity. The secondary metabolites of subfractions are alkaloid, fenol, flavonoid, and steroid/terpenoid.
\end{abstract}

Key Words: bioautography TLC, chromatography, secondary metabolite

\begin{abstract}
ABSTRAK
Penelitian ini mengenai aktivitas antibakteri dan antioksidan dalam isolat fraksi etil asetat dari buah Libo (Ficus variegata Blume.) telah dilakukan dengan tujuan untuk mengetahui aktivitas antibakteri dan antioksidan dalam isolat fraksi etil asetat dari buah Libo. Ekstraksi dilakukan menggunakan metode maserasi dengan pelarut metanol dan $n$-heksan. Isolasi dilakukan dengan menggunakan dua metode yaitu kromatografi kolom vakum (KCV) dan dilanjutkan dengan kromatografi kolom konvensional (KK). Eluen yang digunakan yaitu $n$-heksan-etil asetat. Hasil pemisahan yang diperoleh berdasarkan kromatografi kolom konvensional yaitu sebanyak 4 isolat fraksi. Isolat fraksi tersebut kemudian dilakukan pengujian secara kualitatif yaitu pengujian aktivitas antibakteri menggunakan metode kromatografi lapis tipis (KLT) bioautografi dan dilakukan pengujian aktivitas antioksidan menggunakan metode DPPH. Hasil penelitian yang diperoleh berupa profil kromatografi isolat fraksi F1 dan F4 diperoleh satu spot noda pada plat KLT sedangkan pada F2 dan F3 diperoleh dua spot noda pada plat KLT. Semua fraksi yang diperoleh memiliki aktivitas antibakteri dan antioksidan. Kandungan metabolit sekunder dari fraksi-fraksi aktif tersebut antara lain alkaloid, fenol, flavonoid, dan steroid/terpenoid.
\end{abstract}

Kata Kunci: KLT bioautografi, kromatografi, metabolit sekunder 


\section{PENDAHULUAN}

Indonesia memiliki beraneka ragam tanaman yang berkhasiat sebagai obat. Khususnya pulau Kalimantan yang memiliki tanaman khas yaitu tanaman Libo (Ficus variegata Blume.). Tanaman Libo merupakan tanaman asli dari Kalimantan Timur yang telah dilakukan pengujian dan terbukti memiliki aktivitas antibakteri dan antioksidan (Rusli, 2015).

Infeksi bakteri di Indonesia semakin lama semakin meningkat. Sehingga penggunaan antibiotik kini semakin besar akibatnya resistensi dari pengguna antibiotik semakin meningkat. Oleh karena itu, diperlukan alternatif lain untuk dapat menyelesaikan masalah tersebut.

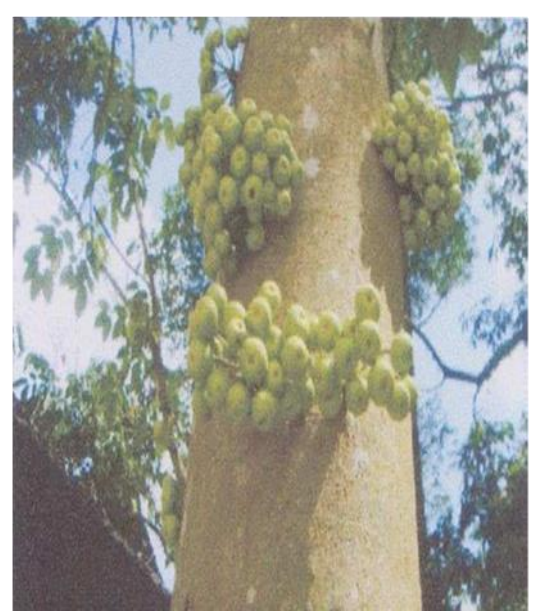

Gambar 1. Tanaman Libo (Ficus variegata Blume.)

Kemudian kebiasaan individu di Indonesia ini masih dikategorikan memiliki pola hidup yang kurang sehat. Salah satunya adalah kebiasaan merokok. Asap rokok memiliki radikal bebas yang apabila secara berlebihan masuk ke dalam tubuh manusia maka akan mengakibatkan penyakit degeneratif. Senyawa yang mampu menetralisir radikal bebas tersebut disebut antioksidan. Sehingga peneliti ingin meneliti suatu tanaman khas Kalimantan yang dapat beraktivitas sebagai antibakteri dan antioksidan. Salah satunya adalah tanaman Libo. Bagian yang diambil adalah bagian buahnya karena buah Libo memiliki waktu pertumbuhan yang cepat sehingga berbuah secara terus menerus dan mudah diperoleh (Rijai, 2013).

\section{METODE PENELITIAN}

\section{Alat dan Bahan}

Alat yang digunakan yaitu peralatan kromatografi lapis tipis (KLT), peralatan kromatografi kolom vakum (KCV), peralatan kromatografi kolom konvensional (KK), lampu UV 254 \& $366 \mathrm{~nm}$, rotary evaporator (büchi rotavapor R-200), alat-alat kaca dan alat non kaca, inkubator (Frailabo ${ }^{\circledR}$ ), autoklaf (Tomy SN-700 ${ }^{\circledR}$ ), Laminar Air Flow (LAF) (Nuarire-126-400E ${ }^{\circledR}$ ) dan Spektroskopi IR. Bahan yang digunakan yaitu buah tanaman Libo, silika gel GF 60, metanol p.a, $n$-heksan p.a, etil asetat, kloroform, aquades, DPPH (2,2 diphenyl-1-pcrylhidrazyl) (Sigma Aldrich), medium NA (Nutrient Agar), bakteri Escherichia coli (bakteri gram negatif) dan Staphylococcus aureus (bakteri gram positif), pereaksi Mayer dan Dragendorff, $\mathrm{FeCl}_{3}, \mathrm{H}_{2} \mathrm{SO}_{4}, \mathrm{CH}_{3} \mathrm{COOH}$ anhidrat, dan $\mathrm{HCl}$. 


\section{Prosedur Kerja}

Sampel buah Libo (Ficus variegata Blume.) dibuat menjadi simplisia kemudian diekstraksi menggunakan metode maserasi dengan pelarut $n$-heksan selama \pm 3 hari pada suhu kamar. Kemudian dimaserasi kembali dengan menggunakan pelarut metanol \pm 3 hari pada suhu kamar. Ekstrak kasar metanol difraksinasi dengan etil asetat sehingga diperoleh ekstrak fraksi etil asetat. Ekstrak fraksi etil asetat dipisahkan dengan menggunakan metode kromatografi kolom vakum (KCV) menggunakan silika gel GF 60. Eluen yang digunakan yaitu $n$-heksan:etil asetat dengan berbagai macam perbandingan. Fraksi yang diperoleh kemudian dilanjutkan pemisahan dengan metode kolom konvensional (KK). Hasil pemisahan dilakukan pengujian aktivitas antibakteri dan antioksidan.

Pengujian antibakteri menggunakan metode KLT bioautografi. Bakteri uji yang digunakan adalah Escherichia coli dan Staphylococcus aureus. Pengujian antioksidan menggunakan metode penyemprotan DPPH. DPPH dibuat dalam konsentrasi $80 \mathrm{ppm}$. Isolat fraksi yang memiliki aktivitas antibakteri dan antioksidan selanjutnya dilakukan pengujian metabolit sekunder.

Setelah pengujian metabolit sekunder, dilakukan penentuan spektrum Infrared (IR) pada sampel. Sampel yang digunakan adalah sampel F1 dan F4. Spektrum IR tersebut dihasilkan dari pentransmisian cahaya yang dapat melewati sampel, pengukuran intensitas cahaya dengan detektor dan dibandingkan dengan intensitas tanpa sampel sebagai fungsi panjang gelombang. Spektrum IR yang diperoleh kemudian diplot sebagai intensitas fungsi energi, panjang gelombang $(\mu \mathrm{m})$ atau bilangan gelombang $\left(\mathrm{cm}^{-1}\right)$ (Anam, 2007). Sehingga dapat dilakukan untuk uji spektrum IR dari masing-masing sampel tersebut.

\section{HASIL DAN PEMBAHASAN}

Ekstraksi simplisia buah Libo (Ficus variegata Blume.) kering sebanyak 674,29 gram menghasilkan ekstrak kasar sebanyak 3,1730 gram. Maserasi merupakan metode ekstraksi cara dingin yang sederhana dan tepat untuk digunakan pada simplisia buah yang diduga mengandung antioksidan karena senyawa antioksidan mudah teroksidasi pada proses pemanasan. Menurut Lizma Febrina, dkk (2015), kondisi optimum ekstraksi pada daun Libo adalah metode sokhlet (cara panas). Namun metode ini tidak dapat digunakan pada ekstraksi buah Libo karena buah Libo mengandung senyawa antioksidan yang apabila melalui proses pemanasan dapat menguraikan senyawa antioksidan tersebut sehingga aktivitas antioksidan pada sampel akan berkurang. Dimaserasi terlebih dahulu dengan pelarut $n$-heksan karena untuk memisahkan buah dengan getahnya kemudian pelarut metanol karena sifat kepolarannya yang dapat melarutkan baik senyawa polar maupun senyawa non polar. Ekstrak kasar 2,5 gram difraksinasi dengan menggunakan metode kromatografi kolom vakum (KCV) dengan pelarut etil asetat menghasilkan fraksi etil asetat kering sebanyak 1,7843 gram. 


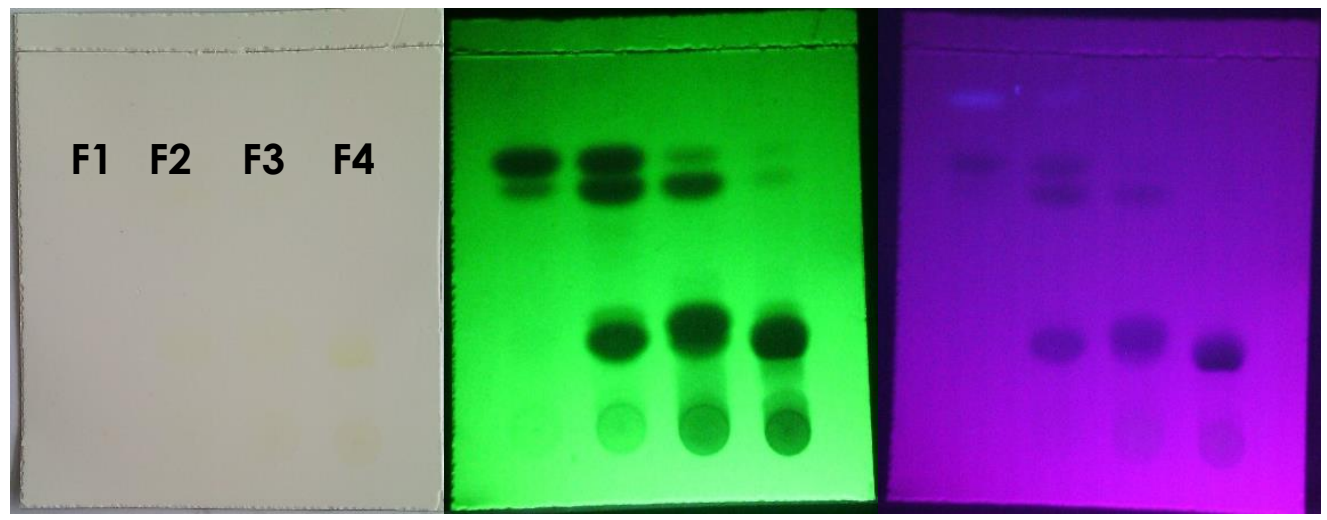

Gambar 2. Hasil KLT 4 isolat fraksi menggunakan eluen $n$-heksan:etil asetat (8:2) diamati pada sinar tampak, sinar UV $254 \mathrm{~nm}$ dan $366 \mathrm{~nm}$

Fraksi etil asetat tersebut kemudian dipisahkan dengan menggunakan kromatografi kolom konvensional (KK) menghasilkan 4 isolat fraksi. Eluen yang digunakan adalah $n$ heksan:etil asetat (10:1), (9:1), (8:2), dan (7:3). Isolat fraksi tersebut selanjutnya dilakukan uji antibakteri dan antioksidan. Hasil dari pengujian antibakteri dan antioksidan isolat fraksi tersebut dapat dilihat pada tabel 1, gambar 3, gambar 4 dan gambar 5.

Tabel 1. Hasil pengujian aktivitas antibakteri dan antioksidan isolat fraksi etil asetat.

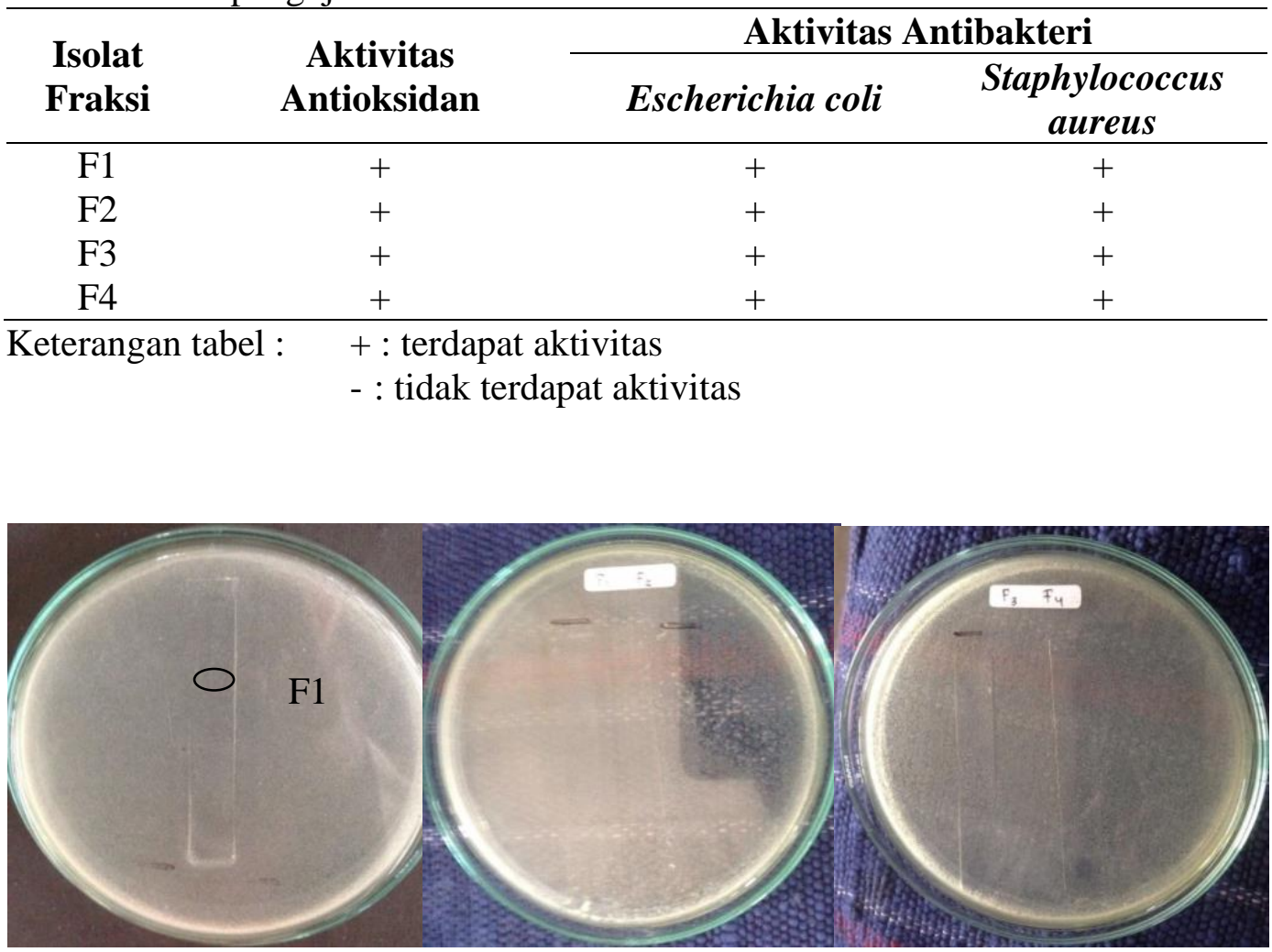

Gambar 3. Hasil positif pengujian antibakteri isolat fraksi etil asetat yang ditunjukkan dengan garis hitam yang menampakkan adanya zona bening pada medium agar terhadap bakteri E. coli. 


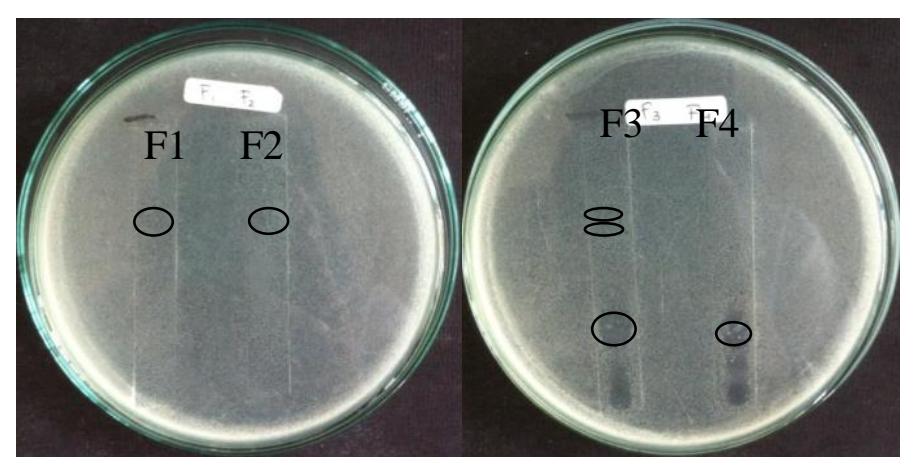

Gambar 4. Hasil positif pengujian antibakteri isolat fraksi etil asetat yang ditunjukkan dengan garis hitam yang menampakkan adanya zona bening pada medium agar terhadap bakteri $S$. aureus.
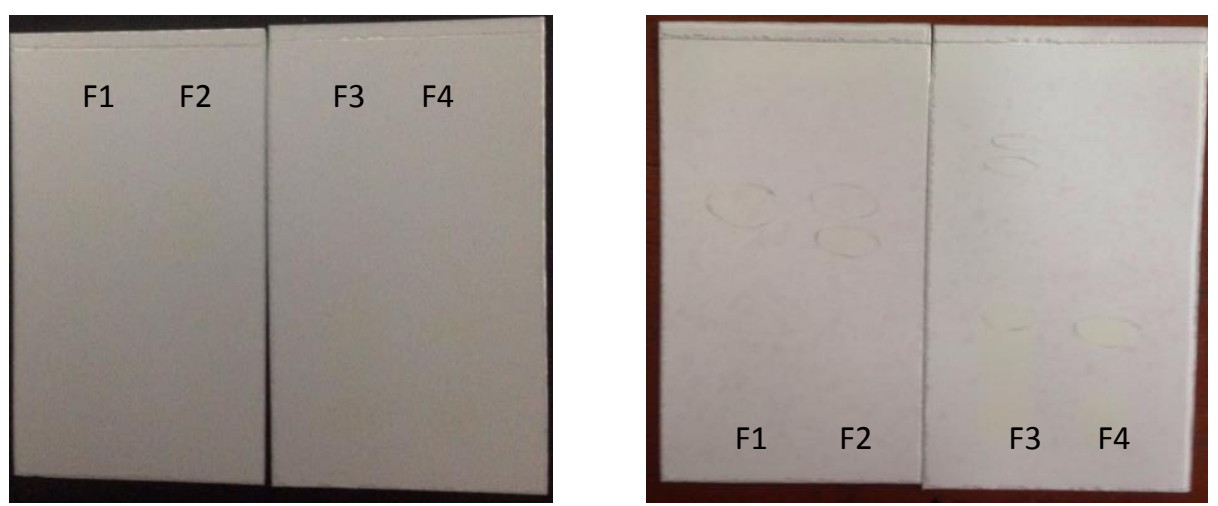

Gambar 5. Hasil positif pengujian antioksidan isolat fraksi etil asetat yang ditunjukkan dengan bulatan hitam yang menampakkan adanya perubahan warna dari putih menjadi kuning pucat.

Berdasarkan tabel 1, gambar 3, gambar 4, dan gambar 5 terlihat bahwa keempat isolat fraksi memiliki aktivitas sebagai antibakteri dan antioksidan. Hasil positif dari pengujian antibakteri ditandai dengan adanya zona bening pada medium yang digunakan. Zona bening yang terbentuk yaitu akibat dari senyawa antibakteri pada isolat fraksi yang berdifusi ke permukaan medium dan menghambat pertumbuhan bakteri uji yang digunakan. Zona bening menandakan tidak terjadinya pertumbuhan bakteri. Hasil positif antioksidan disebabkan oleh kemampuan senyawa antioksidan pada isolat fraksi yang dapat memudarkan warna DPPH. DPPH merupakan radikal bebas yang tidak stabil karena terdapat elektron yang tidak berpasangan, dalam larutan metanol akan berwarna ungu. Pemucatan warna DPPH menunjukkan adanya jumlah elektron yang ditangkap oleh radikal DPPH sehingga dapat diartikan sebagai aktvitas antioksidan dari suatu sampel (Rusli, 2015). Pengujian antibakteri dan antioksidan dilakukan secara kualitatif.

Pengujian kandungan metabolit sekunder dilakukan dengan tujuan mengetahui dugaan golongan metabolit sekunder yang dimiliki oleh buah Libo dan memiliki aktivitas sebagai antibakteri dan antioksidan. Kandungan metabolit sekunder yang terdapat pada isolat fraksi etil asetat dapat dilihat pada tabel 2. 
Tabel 2. Hasil pengujian metabolit sekunder isolat fraksi etil asetat aktif antioksidan dan antibakteri

\begin{tabular}{cccccc}
\hline Isolat & \multicolumn{5}{c}{ Metabolit Sekunder } \\
\cline { 2 - 6 } Fraksi & Alkaloid & Fenol & Flavonoid & Saponin & Steroid/Terpenoid \\
\hline F1 & + & + & + & - & + \\
F2 & + & + & + & - & + \\
F3 & + & + & + & - & + \\
F4 & + & + & + & - & + \\
\hline
\end{tabular}

Keterangan tabel : $\quad+$ : teridentifikasi metabolit sekunder

- : tidak teridentifikasi metabolit sekunder

Berdasarkan tabel 2, terlihat bahwa semua isolat fraksi memiliki kandungan metabolit sekunder yang sama, yaitu mengandung alkaloid, fenol, flavonoid, dan steroid/terpenoid. Sedangkan saponin tidak terkandung pada semua sampel isolat fraksi etil asetat buah Libo. Flavonoid merupakan senyawa antioksidan yang potensial. Begitu pula alkaloid dan terpenoid, terpenoid terbukti mempunyai potensi aktivitas antioksidan dan efek yang protektif melawan oksidatif stress di dalam mitokondria terutama terpenoid lipofilik. Alkaloid juga memiliki aktivitas antioksidan yang dapat bertindak sebagai peredam hidroksi radikal (Sarker, 2009).

Untuk memperkuat prediksi senyawa yang paling berperan dalam aktivitas antibakteri dan antioksidan maka dilakukan uji spektrum IR pada isolat fraksi etil asetat yang hanya memiliki satu noda karena diduga telah memiliki satu spot noda untuk satu senyawa aktif. Adapun hasil spektrum IR dapat dilihat pada gambar 6.

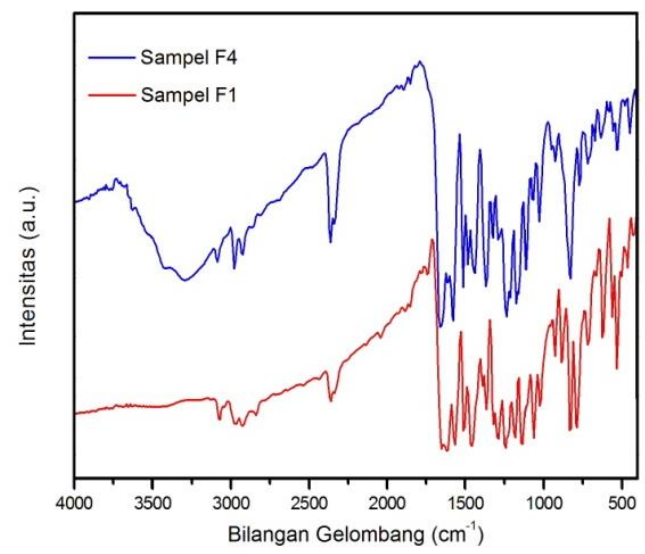

Gambar 6. Hasil spektrum IR sampel F1 dan F4

Berdasarkan hasil spektrum IR diatas dapat terlihat bahwa pada sampel F1 mengandung aromatik $\left(717,52 \mathrm{~cm}^{-1}\right), \mathrm{C}$-benzen para $\left(786,96 \mathrm{~cm}^{-1}-833,25 \mathrm{~cm}^{-1}\right), \mathrm{C}$-O eter $\left(1180,44 \mathrm{~cm}^{-1}-1242,16 \mathrm{~cm}^{-1}\right), \mathrm{CH}_{3}\left(1458,18 \mathrm{~cm}^{-1}\right), \mathrm{C}=\mathrm{O}\left(1743,65 \mathrm{~cm}^{-1}\right), \mathrm{CH}$ alifatik $\left(2839,22 \mathrm{~cm}^{-1}-2924,09 \mathrm{~cm}^{-1}\right)$, dan OH $\left(3487,30 \mathrm{~cm}^{-1}\right)$. Hasil spektrum IR pada sampel F4 mengandung aromatik $\left(717,52 \mathrm{~cm}^{-1}\right.$ dan $\left.1512,19 \mathrm{~cm}^{-1}\right), \mathrm{C}$-benzen para $\left(825,53 \mathrm{~cm}^{-1}\right), \mathrm{C}-\mathrm{O}$ eter $\left(1234,44 \mathrm{~cm}^{-1}\right), \mathrm{CH}\left(1365,6 \mathrm{~cm}^{-1}\right), \mathrm{CH}_{3}\left(1435,04 \mathrm{~cm}^{-1}\right), \mathrm{C}=\mathrm{O}\left(2337,72 \mathrm{~cm}^{-1}\right), \mathrm{CH}$ alifatik $\left(2924,09 \mathrm{~cm}^{-1}-2978,09 \mathrm{~cm}^{-1}\right)$, dan $\mathrm{OH}\left(3294,43 \mathrm{~cm}^{-1}\right)$. Kedua sampel memiliki golongan senyawa yang sama yaitu diduga termasuk golongan flavonoid (Sariningsih, 2015). 


\section{KESIMPULAN}

Berdasarkan data yang telah diperoleh dapat disimpulkan bahwa isolat fraksi etil asetat memiliki aktivitas sebagai antibakteri dan antioksidan, mengandung alkaloid, fenol, flavonoid, dan steroid/terpenoid. Berdasarkan hasil data spektrum IR, diduga termasuk golongan flavonoid.

\section{DAFTAR PUSTAKA}

[1] Anam, Choirul, Sirojudin, K Sofjan Firdausi. 2007. Analisis Gugus Fungsi pada Sampel Uji, Bensin, dan Spiritus Menggunakan Metode Spektroskopi FTIR. Berkala Fisika, Vol 10 No 1. ISSN : 1410-9662.

[2] Rusli, R., Hardina, M.P., Muflihah, F., Rahmadani, A., 2015. Profil Kromatografi Senyawa Aktif Antioksidan dan Antibakteri Fraksi N-Heksana Daun Libo (Ficus variegata Blume.). Journal of Tropical Pharmacy and Chemistry, 3. (2). 124-130. DOI: https://doi.org/10.25026/jtpc.v3i2.98.

[3] Febrina, Lizma, Rolan Rusli, Fairul Muflihah. 2015. Optimalisasi Ekstraksi dan Uji Metabolit Sekunder Tumbuhan Libo (Ficus Variegate Blume.). Journal of Tropical Pharmacy and Chemistry, 3. (2). 74-81. DOI: https://doi.org/10.25026/jtpc.v3i2.153.

[4] Rijai, Laode. 2013. Potensi Tumbuhan Libo (Ficus variegata Blume.) Sebagai Sumber Bahan Farmasi Potensial. Journal of Tropical Pharmacy and Chemistry, 2. (3). 166179. DOI: https://doi.org/10.25026/jtpc.v2i3.63

[5] Sariningsih, Putu, Wiwik Susanah Rita, dan Ni Made Puspawati. 2015. Identifikasi dan Uji Aktivitas Senyawa Flavonoid dari Ekstrak Daun Trembesi (Samanea saman (Jacq.) Merr) Sebagai Pengendali Jamur Fusarium sp. Pada Tanaman Buah Naga. Jurnal Kimia, Vol 9 No 1.

[6] Sarker, S.D. dan Nahar L. 2009. Kimia Untuk Mahasiswa Farmasi Bahan Kimia Organik, Alam dan Umum. Yogyakarta : Pustaka Pelajar. 